\title{
Derin Öğrenme Kullanarak Tiroid Kanseri Teşhisi
}

\author{
Zeynep İlkılıç Aytaç ${ }^{1}$, İsmail İşeri ${ }^{2 *}$, Beşir Dandı1 ${ }^{3}$ \\ ${ }^{1}$ Ondokuz Mayıs Üniversitesi, Yeşilyurt Meslekyüksekokulu, Elektrik ve Otomasyon Bölümü, Samsun, Türkiye (ORCID: 0000-0003-1828-1181) \\ ${ }^{2}$ Ondokuz Mayıs Üniversitesi, Mühendislik Fakültesi, Bilgisayar Mühendisliği Bölümü, Samsun, Türkiye (ORCID: 0000-0002-0442-1406) \\ ${ }^{3}$ Mustafa Kemal Üniversitesi, Mühendislik Fakültesi, Elektril Elektronik Mühendisliği Bölümü, Antakya,Türkiye (ORCID: 0000-0002-3625-5027)
}

(International Symposium on Multidisciplinary Studies and Innovative Technologies (ISMSIT) 2021 - 21-23 October 2021)

(DOI: 10.31590/ejosat.1011166)

\begin{abstract}
ATIF/REFERENCE: İlkılıç Aytaç, Z., İşeri, İ. \& Dandıl, B. (2021). Derin Öğrenme Kullanarak Tiroid Kanseri Teşhisi. Avrupa Bilim ve Teknoloji Dergisi, (29), 292-298.

$\ddot{\mathbf{O} z}$

Geçmişten günümüze yapay zekanın kullanım alanları giderek artmaktadır ve en çok kullanılan alanlardan biri de sağlık sektörüdür. Özellikle tıbbi görüntülerin işlenmesinde oldukça başarılı sonuçlar vermesi ile bir yapay zekâ algoritması olan derin öğrenme, bu görüntülerin işlenmesi ve yorumlanması konusunda sıkça tercih edilmektedir. Son yıllarda dünya çapında artan kanser oranlarıyla birlikte gelişen görüntüleme teknikleri bu hastalıkların teşhisi ve tanısı konusunda uzmanlara oldukça faydalı hale gelmiş̧ir. Bu çalışmanın temel amacı sitopatologlar tarafından manuel olarak yapılan teşhis etme biçiminden esinlenerek derin öğrenmeye dayalı bir çalışma gerçekleştirilmiştir. Bu algoritma bir derin öğrenme mimarisi olan evrişimsel sinir ağı kullanılmıştır Evrişimsel sinir ağı, tanısal olarak ilgili görüntü bölgelerini tanımlayarak önceden belirlenen malignite skolarlarını atar ve bu sayede malignite tahmini yapılır. Deneysel sonuçlar önerilen çalışmanın uzmanlarla karşılaştırılabilir bir performans elde ederek sitopatologlara ikinci bir görüş sağlayabildiğini ve iş yükünü azalttığını göstermektedir.
\end{abstract}

Anahtar Kelimeler: Derin Öğrenme, Evrişimsel Sinir Ağı, Yapay Zeka, Tiroid Kanseri.

\section{Diagnosing Thyroid Cancer Using Deep Learning}

\begin{abstract}
From past to present, the usage areas of artificial intelligence are increasing and one of the most used areas is the health sector. Deep learning, which is an artificial intelligence algorithm with its very successful results in the processing of medical images, is frequently preferred for the processing and interpretation of these images. Imaging techniques, which have developed with the increasing cancer rates worldwide in recent years, have become very useful to experts in the diagnosis and diagnosis of these diseases. The main purpose of this study is to carry out a deep learning-based study inspired by the manual diagnosis method by cytopathologists. This algorithm is used in convolutional neural network, which is a deep learning architecture. Convolutional neural network defines diagnostically relevant image regions and assigns predetermined malignancy scolars, and thus malignancy prediction is made. Experimental results show that the proposed study can achieve a performance comparable to that of experts, providing cytopathologists with a second opinion and reducing their workload.
\end{abstract}

Keywords: Deep Learning, Convolutional Neural Network, Artificial Intelligence, Thyroid Cancer. 


\section{Giriş}

Yapay zekâ insan müdahalesi olmadan bilgisayarla çeşitli görevleri yapmak üzere tasarlanmış genel bir terimdir [1]. Genel amacı, insanların içinde bulunduğumuz modern çağa uyum sağlayabilmesi için insan düşünme biçimini taklit ederek iş verimliliğini arttırmayı esas almaktır. Geçmişten günümüze kadar hayatımızın birçok alanın da araştırılmış ve uygulanmaya başlamıştır [2]. Günümüzde yapay zekâ, tıbbi tarama ve görüntülerde teşhis koyarak bununla birlikte sağlık çalışanlarının iş yükünü azaltmak amacıyla birçok avantaj sağlamaktadır.

Patolojik alanda yapay zekanın kullanılması ile teşhis doğruluğu artarken, patologların iş yükü azaltılarak daha verimli ve üst düzey sonuçlar elde etmeleri sağlanmıştır [3]. Algoritma yapılarının teknoloji ile gelişmesiyle birlikte yapay zekanın (AI), en çok da derin öğrenme tabanlı (DL) yapay zekanın kullanımında artış başlamıştır. Özellikle tümör tespitinde çeşitli problemlerin çözümü için derin öğrenme tabanlı yaklaşımlar kullanılmıştır. Derin öğrenme yapıları iç içe nöron katmanlarından oluşmakta ve birden fazla özellik seviyesinin öğrenilmesine dayanmaktadır. Üst seviyelerdeki özellikler alt seviyelerdeki özelliklerden elde edilerek birden çok verinin öğrenmesine dayanan bu yöntem derin öğrenmenin temelini oluşturur. Derin öğrenme manuel olarak özellik çıkarmak yerine denetimli/denetimsiz özellik öğrenmesi veya hiyerarşik özellik çıkarımı için etkin algoritmalar kullanır. Son yıllarda bir derin öğrenme mimarisi olan evrişimli sinir ağlarını tıbbi görüntüleri analiz etmek ve bu görüntülerden hastalık teşhis etmek için kullanmak popüler bir uygulama haline gelmiştir. Birçok hastalık çeşidinin ultrason görüntüleri derin öğrenme ile analiz edilebilmektedir. Tiroid malignitesi de bu hastalık türlerinden biridir. Tiroid hastalarının ultrason görüntülerini benign ve malign olarak ayırt etmek için çeşitli yöntemler geliştirilmiş ve derin öğrenme yöntemleri de bu yöntemlerden biridir. Tiroid kanseri, tiroid bezinden kaynaklanan bir malignitedir ve genel olarak tiroid nodülü olan hastalarda bulunur. Malignite değerlendirmesi boyun ultrasonografisi görüntülerinden yapılır ve nodüller palpasyonla veya ultrason görüntüleme ile tespit edilebilir.

Gupta N.vd., tiroidin papiller ve foliküer neoplazilerinde yapay zeka ile görüntü analizi yaparak ayırt edici tanısal etkinliğini değerlendirmek üzere çalışmışlardır. Toplam 60 vaka incelemiş ve bu vakalardan 44 vakayı eğitim seti için, 16 vakayı test seti için kullanmışlardır. İyi huylu ve kötü huylu tiroid lezyonlarınnı ayırt etmede oldukça başarılı olduğu sonucuna varmışlardır [4]. Daskalakis A. vd., benign ve malign tiroid nodüllerini rutin olarak alınan (FNA, H \& E lekeli) sitolojik görüntülerden teşhis edebilmek için çalışmışlardır. Çok sınıflandırıcı bir sistem oluşturmaya çalışmışlar ve önerilen yöntemin sitopatologların kesin tanı koymada karar verebilmesine destek olmasını amaçlamışlardır [5]. Selvathi D. vd., iyi huylu ve kötü huylu tiroid lezyonlarını birbirinden ayırt etmek için çalışmışlardır. Bunun için iki tane modül önermişlerdir. Tiroid görüntülerini SVM (destek vektör makinesi) ve ELM (aşırı öğrenme makinesi) kullanarak sınıflandırıp normal tiroid görüntüsünden tiroid nodüllerinin segmentasyonunu sağlamışlardır. Yapılan çalışma neticesinde ELM'nin SVM'den daha iyi segmentasyon doğruluğuna sahip olduğu sonucuna varılmıştır [6]. Ding J. vd., tiroid nodüllerini iyi huylu ve kötü huylu olarak sınıflandırabilmek için bir MIL

e-ISSN: 2148-2683 (çoklu örnek öğrenme) yöntemi kullanmıştır. Çalışmada tiroid B-modu ultrason görüntüleri kullanılmıştır. Ultrason görüntülerindeki lezyonu sınflandırmak için SVM kullanılmıştır. Deneysel sonuçlar önerilen yaklaşımın iyi bir performansa ulaştığını göstermiştir [7]. Ma J.vd., tiroid görüntülerindeki heterojen görünümler ve arka planların görüntülerde nodül tespiti için zorluk çıkardığını ve tiroid nodüllerinin ultrason görüntülerinden daha doğru bir şekilde ayrıştırılması işlemi için CNN kullanmıştır. CNN benign ve malign tiroid görüntü parçalarını girdi olarak kullanmış ve çıktı olarak segmentasyon olasılık haritaları üretmiştir. Denseysel sonuçlar önerilen yöntemin nodül tespiti için oldukça iyi performans gösterdiğini ve CNN'nin nodülleri doğru ve etkili bir şekilde tanımlayabildiğini göstermiştir [8]. Li H. vd., tiroid ultrason görüntülerinden tiroid kanserinin tespiti için derin öğrenme yaklaşımını kullanmıştır. Ultrason görüntülerindeki bulanıklık, belirsizlik ve düzensiz şekiller için $\mathrm{CNN}$ yöntemini kullanmışlardır. Ancak CNN'nin doğrudan kullanılması yerine Faster R-CNN kullanarak daha uygun bir algilayıc1 geliştirmişlerdir. Daha doğru bir algılama sonucu elde edebilmek için CNN'ye uzamsal kısıtlı bir katman ekleyerek kanser bölgelerinin bulunduğu alanı çevreleyen bölgenin özelliklerini çıkarabilmişlerdir. Deneyler bu yöntemin patologların iş yükünü azalttığını ve tiroid kanserinin insan müdahalesi olmadan tespit edilebileceğini göstermiştir [9].

\section{Materyal ve Metot}

\subsection{Evrişimli Sinir Ağları ve Yapısı}

1970'li yıllardan beri CNN'ler üzerine birçok çalışma yapılmıştır [10,11]. Sirinukunwattana K. vd., histopatoloji görüntülerinden sinıflandırma yapmak ve kanserli dokuları bulabilmek için CNN kullanmıştır. Farklı histolojik derecelerdeki örneklerden alınan 20.000'den fazla çekirdek içeren büyük bir veri kümesi üzerinde değerlendirme yapılmıştır [12]. Kraus O.Z. vd., mikroskop görüntülerini snıflandırmak ve segmentlere ayırmak için CNN'leri çoklu örnek öğrenimiyle (MIL) birleştiren bir yaklaşım geliştirmişlerdir. MIL'de kullanılan toplama işlevi ve CNN'de kullanılan havuzlama katmanları arasındaki benzerliği kullanmışlardır. CNN'leri MIL ile birleştirip mikroskop görüntüleri ile eğitim işlemini sağlamışlardır [13]. Tajbakhsh N. vd., CNN'lerin sıfırdan eğitim ihtiyacını ortadan kaldırılıp kaldırılmayacağı üzerine çalışmışlardır. Sonuç olarak kaynak ve hedef veri tabanları arasındaki büyük farklar bu tür bir uygulamanın mümkün olmayacağını göstermiştir. Yapılan deneyler, tıbbi görüntü uygulamaları için CNN'lerin potansiyelinin yüksek olduğunu ve iyi performans gösterdiğini doğrulamıştır. [14]. Roa A. C. vd., patoloji görüntülerinden hastalığın otomatik olarak saptanması için çalışmalar yapmıştr. Patologların manuel olarak teşhis koyma zorluğunun üstesinden gelmek amaciyla bu konuya odaklanmışlardır. Yapılan çalışmada, dijital görüntülerden tümör tespiti yapabilmek için CNN kullanmışlardır. Sınıflandırıcıyı yaklaşık 400 örnek ile eğitip, ardından The Cancer Genome Atlas'tan yaklaşık 200 vakayı bağımsız olarak doğrulamayı içermiştir. [15]. Hou L. vd., Tüm Slayt Doku Görüntüsü (WSI) sınıflandırmasında başarılı olan denetimli bir karar füzyon modeli ve CNN modeli üzerine çalışmışlardır. CNN'nin eğitimi için ayırt edici özellikleri otomatik olarak tanımlayan Beklenti Maksimizasyonu (EM) tabanlı bir yöntem önerilmiştir. Algoritma, patologların teşhisine benzer teşhis koyabilmiş ve kanser alt tiplerini sınıflandırabilmiştir [16]. Esteva A. vd., cilt kanseri sınıflandırması için derin öğrenme yöntemlerini 
kullanmışlardır. Cilt lezyonlarını sınıflandırabilmek için CNN kullanılmış ve piksel ve hastalık etiketleri giriş olarak kullanılmıştır. 129.450 klinik görüntü veri kümesi kullanılarak CNN eğitilmiştir. İki sınıflandırma yöntemini dermatologların performansına göre kıyaslamışlardır. İlk vaka da en yaygın kanserleri tanımlayıp, ikinci vaka da en ölümcül kanserlerin tanımlanmasını temsil etmiştir. CNN yöntemi her iki görevde de uzmanlarınkine eşdeğer bir performans göstermiş ve dermatologlarla karşılaştırılabilir bir yetkinlik göstermiştir [17]. Shi G. vd., 2020 yılında tiroid nodülleriniin sınıflandırılması için yöntemler geliştirmiştir. Yöntem, radyologların teşhisine benzer sonuçlar elde edebilmiştir. 1937 klinik tiroid ultrason görüntüsü kullanılmış ve sonuç olarak \%91,46 doğruluk, \%90,63 duyarlılık, \% 92,65 özgüllük elde etmişlerdir. Deneysel sonuçlar önerilen yöntemin mevcut sınıflandırma yöntemlerinden daha iyi olduğunu göstermiştir [18].
İlk olarak Lecun tarafindan önerilen evrişimli sinir ağları örüntü tanıma alanında en başarılı yöntemlerden biri haline gelmiştir. Evrişimli sinir ağlarında giriş görüntüsünden görselin özelliklerini çıkarmak için yere olarak eğitilen filtreler kullanılmaktadır. Havuzlama işlemi sayesinde özellik haritalarının boyutları küçültülerek bir sonraki evrişime girdi görüntüsü olarak verilir. Bu işlemin amacı derin öznitelikler çıkarmaktır. Sınıflandırıcılar bu özelliklerle ilgili karar verir [19]. Şekil 1'de gösterilen yapı bir CNN yapısı ve bu yapı girişleri küçük evrişim filtrelerine dönüştüren birçok katman içerir.

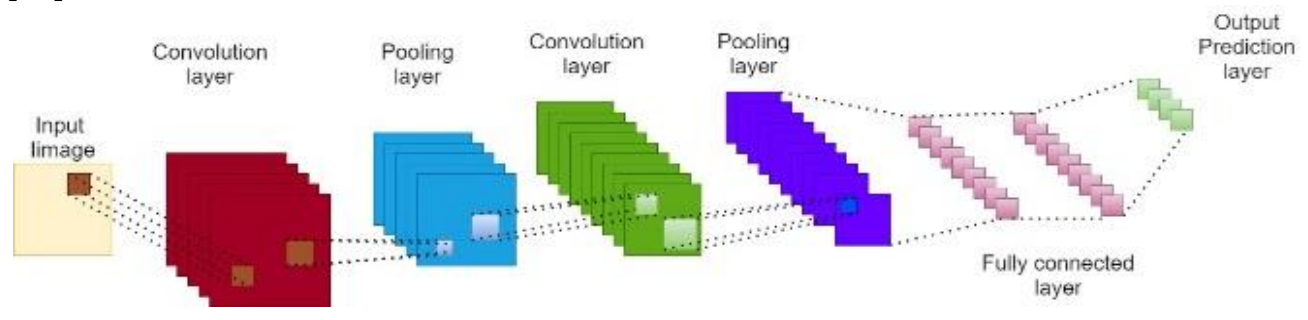

Şekil 1: CNN yapısı

CNN yapıları genelleştirilirse evrişim katmanları, havuzlama katmanları ve tam bağlantılı bir ağ içeren bir yapıyı ifade eder [20]. öznitelik çıkarımı için evrişim işlemleri kullanılır ve sınıflandırıcı olarak tam bağlantılı ă̆ kullanılır. Tam bağlantılı ağ sınıflandırma işlemini sonlandırmak için bir SoftMax çıkış katmanı kullanır. AlexNet, GoogleNet gibi birçok ağ yapısı bu katmanlardan oluşturulmuştur. Eğitim işleminde meydana gelen en büyük sorunlardan biri aşırı uydurmadır. Model aşırı uydurulduğuda eğitim hatası düşer test hatası yükselir buna aşırı uydurma denir. Bunu önlemek için veri arttırma, Dropout ve DropConnect gibi teknikler kullanılabilir $[21,22,23,24]$

\subsubsection{Evrişim}

$\mathrm{Bu}$ işlem giriş görüntüsüne karmaşık işlevlerin uygulanmasına izin veren bir dizi sabit boyulu filtreye sahip bir yapıdır. Yerel olarak eğitilmiş filtrelerin görüntünün üzerinde kaydırılmasıyl gerçekleşir. Her filtre aynı ağırlık ve bias değerine sahiptir. Bu sayede ağırlık paylaşım mekanizması oluşur ve aynı özelliğin tüm görüntü üzerinde temsil edilmesini sağlar [25,20]. Filtrelerin boyutuna göre bir alıcı alan belirlenir. Giriş görüntüsünün boyutu mxn ve çekirdeğin boyutu cxc olsun ve I görüntüyü, w ağırlığı ve b 'de bias'ı temsil etsin. Çıkış aşağıdaki denklemdeki gibi hesaplanabilir:

$$
O_{0,0}=f\left(b+\sum_{t=0}^{c} \sum_{r=0}^{c} w_{t, r} i_{0+t, 0+r}\right)
$$

f, aktivasyon fonksiyonu olarak ifade edilir ve burada aktivasyon fonksiyonu olarak ReLu veya sigmoid kullanılabilir [20]. ReLu aktivasyon fonksiyonu aşağıdaki gibi ifade edilevbilir.

$f(x)= \begin{cases}x, & x>0 \\ 0, & \text { else }\end{cases}$

\subsubsection{Havuzlama}

Özellik haritaları evrişim ve aktivasyon fonksiyonundan geçtikten sonra havuzlama işlemi uygulanır. Havuzlama işlemi daha küçük özellik haritalarının oluşturulmasını sağlar. Görüntünün üzerinde bir pencere kaydırılmasıyla oluşur. Havuzlama işlemleri genel olarak maksimum, ortalama ve L2 havuzlamadır. Maksimum havuzlamada maksimum değer baştan sona geçer, ortalama havuzlamada girdi değerlerinin ortalaması alınır ve L2 havuzlama da da girdilerin L2 normunu hesaplar [20]. Görsel özelliklerinin bağımsız olarak çıkarılmasını ve görüntü boyutunun küçültülmesini havuzlama işlemiyle elde ederiz.

\subsubsection{Tam Bă̆lı Katman}

Evrişim ve havuzlama işleminden sonra veriler tek boyutlu bir vektöre dönüştürülür ve bu vektör tam bağlı ağa giriş olarak verilir. Tam bağlantılı bu yapı, birçok gizli katmandan oluşmaktadır. Her nöron ağırlıkları bir önceki katmandan gelen verilerle çarparak bias değerini ekler. Bu değer bir sonraki katmana iletilmeden önce aktivasyon fonksiyonuna tabi tutulur. Bu katmanda yapılan hesaplamalar aşağıdaki denklemde görülmektedir:

$f\left(c_{1}\right)=f\left(b+\sum_{q=1}^{M} w_{1, q} * O_{q}\right)$

F aktivasyon fonksiyonunu, w ağırlık vektörünü, o q nöronunun girdi vektörünü ve b bias değerini ifade etmektedir.

\subsubsection{SoftMax}

Lojistik regresyonun çok sınıflı uyarlanmış versiyonu olan softMax işlevi etkinleştirme işlevi olarak kullanılır. Genel olarak sınıflandırma amacı ile kullanılır ve aşağıdaki denklemdeki gibi ifade edilebilir: [20] 
$\operatorname{class}_{j}=\frac{\exp \left(s f_{j}\right)}{\sum q \exp \left(s f_{q}\right)}$

\subsubsection{DropOut}

Ezberlemeyi önlemek için kullanılan yöntemlerden biridir. A $\breve{~ y a p ı s ı n d a ~ r a s t g e l e ~ s e c ̧ i l e n ~ b a z ı ~ n o ̈ r o n l a r ı n ~ a k t i v a s y o n u ~ e g ̆ i t i m ~}$ sırasında sıfır alınır. Bu yöntem sayesinde öğrenme süreci daha güvenilir hale gelir ve aşırı uydurma azaltılır [26].

\subsubsection{DropConnect}

Aşırı uydurmayı önlemek için geliştirilmiş ve DropOut'a benzeyen tekniklerden biridir. DropOut tekniğinde seçilen nöronların aktivasyonları sıfır olarak alınırken, bu yöntemde rastgele seçilen ağırlık değerleri sıfira ayarlanır. Bu sayede ağın genelleme performansı artar ve ezberlemeyi önler [27].

\subsection{Veri Seti}

Veri seti uzmanlar tarafindan hazırlanan ultrason görüntülerinden oluşturulmuştur [28]. Tiroid nodüllerini saptamak için bilgisayarlı tomografi (BT) ve ultrason (US) gibi görüntüleme yöntemleri kullanılmaktadır. Kullanılan B modu ultrason görüntüsü maliyet açısından en uygun tekniktir. Tiroid lezyonlarını tanımlamak için nodüller iyi huylu, muhtemel iyi huylu, sınırda, malignite için şüpheli ve malign olarak sinıfladırılmaktadır. Tiroid ultrason görüntülerinden benign ve malign tespitini bilgisayar ortamında yapabilmek için, ultrason görüntüleri öznitelik çıkarma ve sınıflama olmak üzere iki aşamadan geçirilir. $\mathrm{Bu}$ sayede teşhis doğruluğunu arttırma ve gereksiz iş yükünden kurtulma hedeflenmiştir. Önerilen veri tabanı en az iki uzman radyolog tarafindan gerçekleștirilen Tiroid Görüntüleme Raporlama ve Veri Sistemi (TIRADS) sözlüğünü kullanarak 389 vakaya karşıllık gelen B-modu ultrason görüntülerini içermektedir. Hastalar TIRADS tanımına uygun bir şekilde seçilmiştir. Vakalar Kolombiyadaki en büyük tanısal görüntüleme merkezlerinden biri olan ve yllda 2000 'den fazla ince iğne aspirasyon yöntemi ile ilişkili tiroid ultrasonu yapan IDIME Ultrason Departmanından alınmıştır. Hastalar TIRADS tanmına uygun olarak seçilmiştir. Yaşları 35 -57, 2 -16 arasında değişen 270 kadın ve 29 erkek olmak üzere toplam 299 hasta kullanılmıştır. Hastaların TIRADS gerekliliklerini karşılayan spesifik özellikleri tanımlanmıștır. Tiroid ultrason videolarından görüntüleri çıkarmak için TOSHIBA Nemio 30 ve TOSHIBA Nemio MX kullanılmıştır. Görüntüler JPEG formatına dönüştürülüp kaydedilerek segmentlere ayrılmış nodüllerin ve açıklamalı etiketlerin web üzerinden anında paylaşılmasına izin vererek tasarlanan bir görüntü açıklama aracı geliştirilmiştir [28].

Tüm vakalar uzmanlar tarafindan tiroidit, kistik nodül, malign ve iyi huylu nodüller olarak kategorize edilmiştir. Tanılar ultrason özelliklerine dayanmakta ve patolojik raporlarla doğrulanmaktadır. Patolojik tanımlamaya ek olarak BETHESDA (Tiroid Sitopatolojisini Raporlama Sistemi) sonuçları da XML dosyasına eklenmiştir. Tablo 1'de bu sonuçlar görülmektedir. XML dosyaları vakaların ayırt edici bilgilerini, sayılarını hastaların yaş ve cinsiyet bilgilerini içermektedir.

Tablo 1. PATOLOJIK TANI

\begin{tabular}{cl} 
BETHESDA & CASES \\
\hline 1 & 24 \\
2 & 137 \\
3 & 18 \\
4 & 8 \\
5 & 13 \\
6 & 0
\end{tabular}

Tiroid bozukluğu olan 299 hastanın 347 ultrason görüntüsü analiz adilmiştir. Hastalar uzmanlar tarafından TIRADS sistemi kullanılarak sınıflandırılmıştır. Tablo 2 veri setinin gözlemci başına her kategoriden kaç vaka içerdiğini göstermektedir. Burada 200 vaka BETHESDA sistemine göre onaylanmıştır. 24 örnek patoloji çalışması için yetersiz görülmüştür. Görüntü özelliklerini patolojik olarak tanımlayabilmek için TIRADS sistemi kullanılmıştır.

Tablo 2. Her gözlemci için TIRADS sınıflandırmasının dağılımı

\begin{tabular}{|c|c|c|c|c|c|c|}
\hline \multirow[t]{2}{*}{ TIRADS } & \multicolumn{3}{|c|}{$\begin{array}{c}\text { Gözlemci } 1 \\
\text { Teşhis Edilen Vaka Sayısı }\end{array}$} & \multicolumn{3}{|c|}{$\begin{array}{c}\text { Gözlemci } 2 \\
\text { Teşhis Edilen Vaka Sayısı } \\
\end{array}$} \\
\hline & Bayan & Erkek & Toplam & Bayan & Erkek & Toplam \\
\hline 2 & 3 & 35 & 38 & 2 & 18 & 20 \\
\hline 3 & 2 & 12 & 14 & 3 & 30 & 33 \\
\hline $4 a$ & 9 & 76 & 85 & 11 & 79 & 90 \\
\hline $4 b$ & 5 & 70 & 75 & 8 & 93 & 101 \\
\hline $4 \mathrm{c}$ & 6 & 50 & 56 & 1 & 34 & 35 \\
\hline 5 & 4 & 26 & 30 & 4 & 16 & 20 \\
\hline
\end{tabular}

\section{Bulgular}

$\mathrm{Bu}$ çalışmada toplam 105 tiroid ultrason görüntüsü kullanılmış bunlardan 71 görüntü eğitim için 34 görüntü test için kullanılmıştır. Kullanılan veri setinin etiketlenmiş örnekleri e-ISSN: 2148-2683
Tablo 3'de görülmektedir. Etiketlenen veriler TIRADS skorlarına göre etiketlenmiştir. Eğitim işlemi sırasında tiroid ultrason görüntülerinin benign ve malign örneklerini içeren pekçok kombinasyonu kullanılmıştır. 
Tablo 3. Tiroid ultrason görüntülerinin etiketlenmiş görselleri
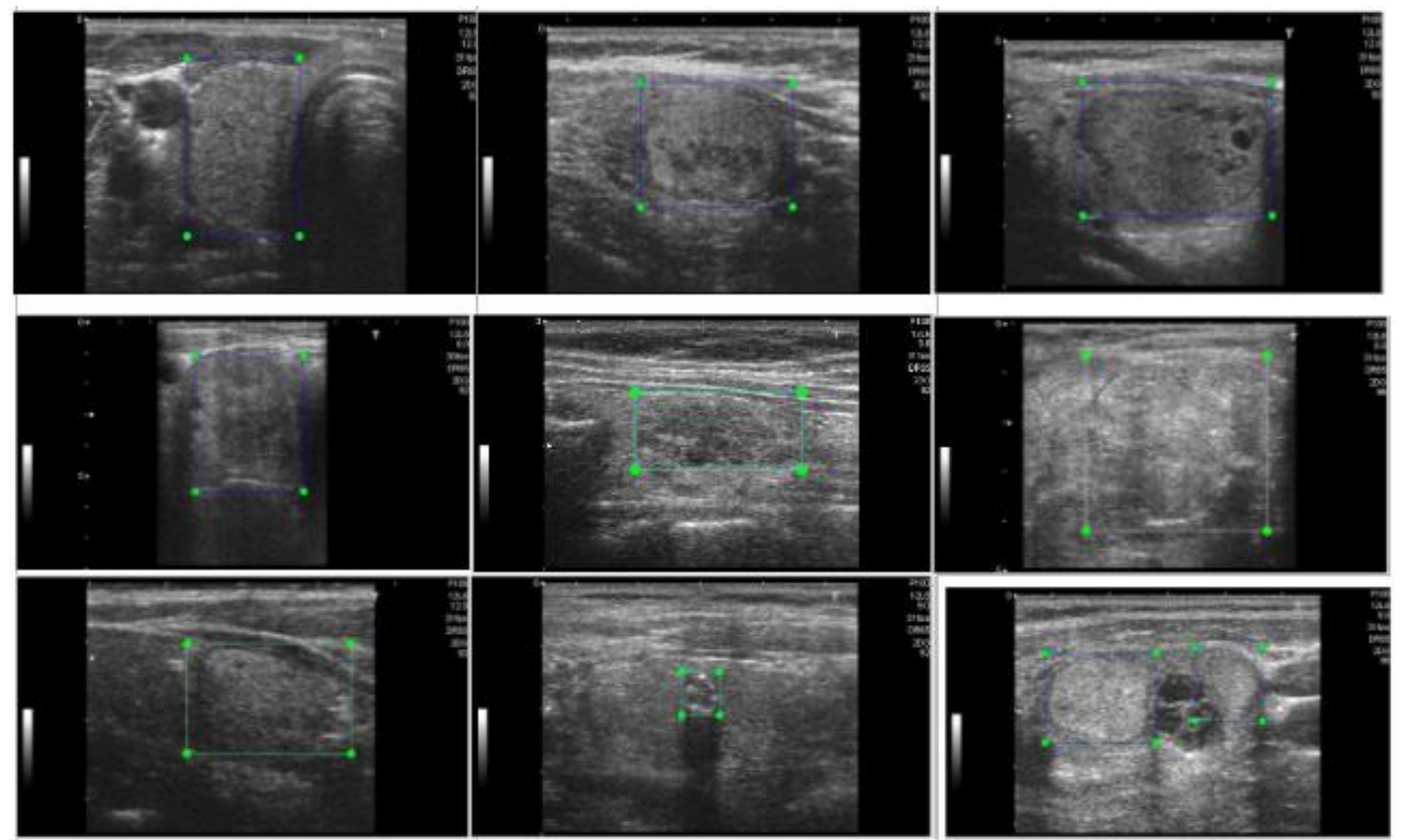

Modelin eğitim işlemi sırasında GPU desteği alabilmek için GoogleColab ortamından yararlanılmıştır. Eğitim işlemi sonrasında TIRADS skorları ile belirlediğimiz kriterlere göre

test olarak verilen görüntülerden elde edilen sonuçlar Tablo 6'dA verilmiștir. Calıșmamızın test verilerine ait confusion matrisi ve Tablo 4'de belirtilmiştir. Bu matrisin performans ölçüleri Tablo 5 'de gösterilmiştir.

Tablo 4. Test işleminin confusion matrisi

\begin{tabular}{|l|l|l|l|l|l|l|}
\hline & $\mathrm{a}$ & $\mathrm{b}$ & $\mathrm{c}$ & $\mathrm{d}$ & $\mathrm{e}$ & $\mathrm{f}$ \\
\hline $\mathrm{a}=$ TIRADS2 & 5 & 0 & 0 & 1 & 0 & 0 \\
\hline $\mathrm{b}=$ TIRADS3 & 2 & 3 & 0 & 1 & 0 & 0 \\
\hline $\mathrm{c}=$ TIRADS4A & 2 & 0 & 5 & 0 & 0 & 0 \\
\hline $\mathrm{d}=$ TIRADS4B & 0 & 0 & 0 & 5 & 0 & 0 \\
\hline $\mathrm{e}=$ TIRADS4C & 2 & 0 & 0 & 0 & 6 & 0 \\
\hline $\mathrm{f}=$ TIRADS5 & 0 & 0 & 0 & 1 & 0 & 3 \\
\hline
\end{tabular}

Tablo5. Test işlemi için performans ölçüleri

\begin{tabular}{|l|r|r|r|r|}
\hline & \multicolumn{1}{|l|}{ Accuracy } & \multicolumn{1}{l|}{ Precision } & \multicolumn{1}{l|}{ Recall } & F1 Score \\
\hline $\mathrm{a}=$ TIRADS2 & $\% 80,56$ & $\% 83,33$ & $\% 45,45$ & $\% 58,82$ \\
\hline $\mathrm{b}=$ TIRADS3 & $\% 91,67$ & $\% 50,00$ & $\% 100,00$ & $\% 66,67$ \\
\hline $\mathrm{c}=$ TIRADS4A & $\% 94,44$ & $\% 71,43$ & $\% 100,00$ & $\% 83,33$ \\
\hline $\mathrm{d}=$ TIRADS4B & $\% 90,63$ & $\% 100,00$ & $\% 62,50$ & $\% 76,92$ \\
\hline $\mathrm{e}=$ TIRADS4C & $\% 93,75$ & $\% 75,00$ & $\% 100,00$ & $\% 85,71$ \\
\hline $\mathrm{f}=$ TIRADS5 & $\% 97,22$ & $\% 75,00$ & $\% 100,00$ & $\% 85,71$ \\
\hline
\end{tabular}



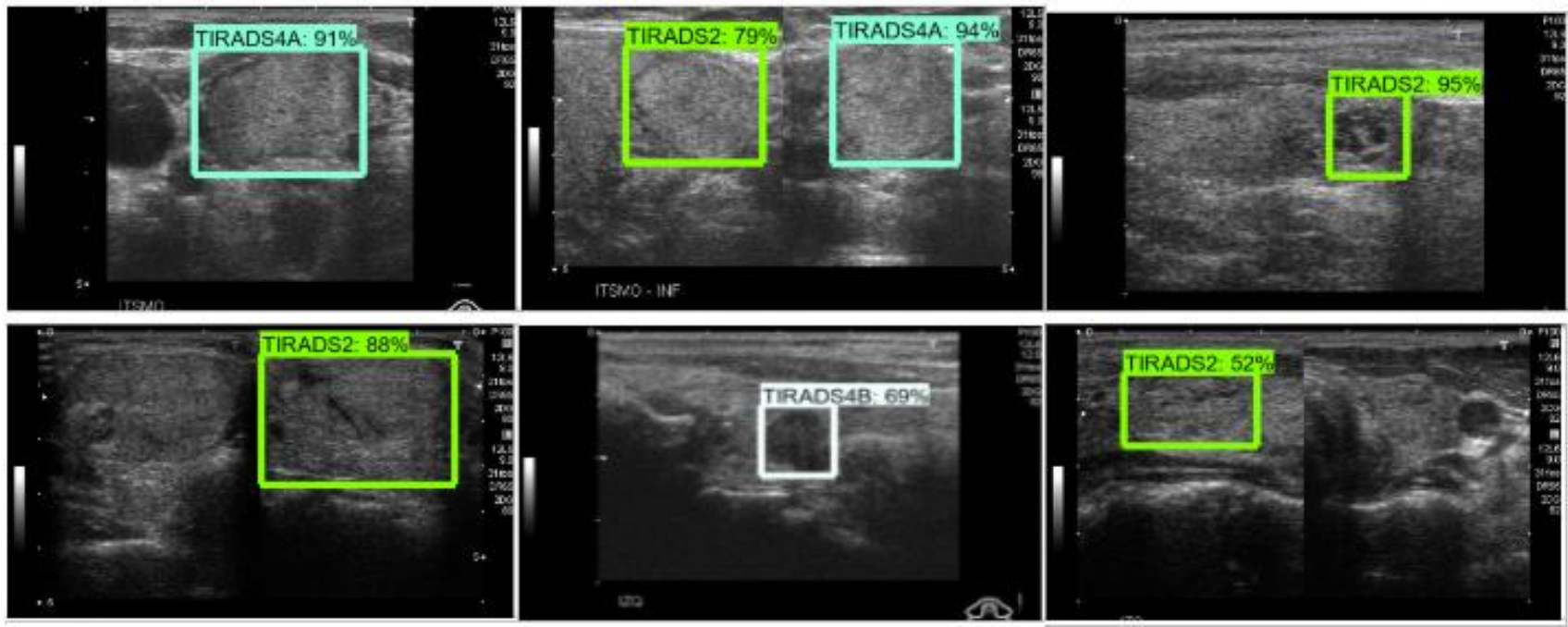

\section{Sonuç}

Teknolojinin gelişmesiyle birlikte birçok alanda yapay zeka tekniklerinin avantajları kullanılmaya başlamıştır. Özellikle son yıllarda kanser oranlarındaki artış ile patologların iş yükü artmaya başlamıştır. Bu yükü azaltmak ve teşhis doğruluğunu arttırmak amacıyla ultrason görüntüleri üzerine derin öğrenme yöntemleri kullanılmaya başlamıştır. Bunlardan en çok kullanılanlardan biri CNN'dir.

$\mathrm{Bu}$ çalışmada patolojide derin öğrenme yaklaşımlarına bir örnek olarak tiroid ultrason görüntüleri üzerine bir derin öğenme yöntemi olan CNN uygulanmıştır. Uzman radyologlar tarafindan belirlenmiş TIRADS skorları esas alınarak ultrason görüntüleri etiketlenmiş ve test edilmiştir. Elde edilen sonuca göre tiroid ultrason görüntülerinden tiroid nodülleri belirlenen TIRADS skorlarına göre tespit edilmiştir. Sonuçlar geliştirilen yöntemin doğruluğunu kanıtlamış ve önerilen bu yöntemin patologların dijital ortamda tiroid nodül tespiti yapabileceğini göstermiştir. $\mathrm{Bu}$ sayede manuel olarak kanserli dokuları teşhis etme zorluğu ve süresi azalarak patologlara ikinci bir görüş sunulabileceği görülmüştür.

\section{Kaynakça}

[1] Du XL, Li WB, Hu BJ. Application of artificial intelligence in ophthalmology. Int J Ophthalmol. 2018;11(9):1555-61.

[2] McCorduck P. Machines who think: a personal inquiry into the his- tory and prospects of artificial intelligence. Natick: A.K. Peters, 2004.

[3] Russell SJ, Norvig P. Artificial intelligence: a modern approach. Upper Saddle River: Prentice Hall, 2003.

[4] Gupta, N., Sarkar, C., Singh, R. ve Karak, A. K. (2001). Evaluation of diagnostic efficiency of computerized image analysis based quantitative nuclear parameters in papillary and follicular thyroid tumors using paraffin-embedded tissue sections. Pathology Oncology Research, 7(1), 46-55.

[5] Daskalakis, A., Kostopoulos, S., Spyridonos, P., Glotsos, D., Ravazoula, P., Kardari, M., Kalatzis, I., Cavouras, D. ve Nikiforidis, G. (2008). Design of a multi-classifier system for discriminating benign from malignant thyroid nodules using routinely $\mathrm{H} \& \mathrm{E}-$ stained cytological images. Computers in biology and medicine, 38(2), 196-203.
[6] Selvathi, D. ve Sharnitha, V. S. (2011). Thyroid classification and segmentation in ultrasound images using machine learning algorithms. In 2011 International Conference on Signal Processing, Communication, Computing and Networking Technologies, 836-841. IEEE.

[7] Ding, J., Cheng, H. D., Huang, J. ve Zhang, Y. (2014). Multiple-instance learning with global and local features for thyroid ultrasound image classification. In 2014 7th International Conference on Biomedical Engineering and Informatics 66-70. IEEE.

[8] Ma, J., Wu, F., Jiang, T. A., Zhao, Q., ve Kong, D. (2017). Ultrasound image-based thyroid nodule automatic segmentation using convolutional neural networks. International journal of computer assisted radiology and surgery, 12(11), 1895-1910. Doi: 10.1007/s11548-017-1649-7

[9] Li, H., Weng, J., Shi, Y., Gu, W., Mao, Y., Wang, Y., Liu, W. ve Zhang, J. (2018). An improved deep learning approach for detection of thyroid papillary cancer in ultrasound images. Scientific reports, 8(1), 1-12. Doi:10.1038/s41598018-25005-7

[10] Fukushima, K., Neocognitron: a self-organizing neural network model for a mechanism of pattern recognition unaffected by shift in position. Biol. Cybern. 36 (4), 193202. doi: 10.10 07/BF0 0344251, 1980.

[11] Lo, S.-C., Lou, S.-L., Lin, J.-S., Freedman, M.T., Chien, M.V., Mun, S.K., Artificial convolution neural network techniques and applications for lung nodule detec- tion. IEEE Trans. Med. Imaging 14, 711-718. doi: 10.1109/42.476112, 1995.

[12] Sirinukunwattana, K., Raza, S. E. A., Tsang, Y. W., Snead, D. R., Cree, I. A. ve Rajpoot, N. M. (2016). Locality sensitive deep learning for detection and classification of nuclei in routine colon cancer histology images. IEEE transactions on medical imaging, 35(5), 1196-1206.

[13] Kraus, O. Z., Ba, J. L. ve Frey, B. J. (2016). Classifying and segmenting microscopy images with deep multiple instance learning. Bioinformatics, 32(12), 52-59.

[14] Tajbakhsh, N., Shin, J. Y., Gurudu, S. R., Hurst, R. T., Kendall, C. B., Gotway, M. B. ve Liang, J. (2016). Convolutional neural networks for medical image analysis: 
Full training or fine tuning?. IEEE transactions on medical imaging, 35(5), 1299-1312.

[15] Cruz-Roa, A., Gilmore, H., Basavanhally, A., Feldman, M., Ganesan, S., Shih, N. N., Tomaszewski, J., Gonzales, F. A. Ve Madabhushi, A. (2017). Accurate and reproducible invasive breast cancer detection in whole-slide images: A Deep Learning approach for quantifying tumor extent. Scientific reports, 7, 46450. Doi: 10.1038/srep46450.

[16] Hou, L., Samaras, D., Kurc, T. M., Gao, Y., Davis, J. E. ve Saltz, J. H. (2016). Patch-based convolutional neural network for whole slide tissue image classification. In Proceedings of the ieee conference on computer vision and pattern recognition, 2424-2433.

[17] Esteva, A., Kuprel, B., Novoa, R. A., Ko, J., Swetter, S. M., Blau, H. M. ve Thrun, S. (2017). Dermatologist-level classification of skin cancer with deep neural networks. nature, 542(7639), 115-118.

[18] Shi, G., Wang, J., Qiang, Y., Yang, X., Zhao, J., Hao, R., Yang, W., Du, Q. ve Kazihise, N. G. F. (2020). Knowledgeguided synthetic medical image adversarial augmentation for ultrasonography thyroid nodule classification. Computer Methods and Programs in Biomedicine, 196, 105611.

[19]Ravi, D., Wong, C., Deligianni, F., Berthelot, M., AndreuPerez, J., Lo, B., et al. (2017). Deep learning for health informatics. IEEE Journal of Biomedical and Health Informatics, 21(1), 4-21.

[20] Nielsen, M. A. (2015). Neural networks and deep learning. Determination Press.

[21]Deng, J., Dong, W., Socher, R., Li, L. J., Li, K., \& Fei-Fei, L. (2009). Imagenet: A large-scale hierarchical image database. In IEEE conference on, Computer vision and pattern recognition, 2009. CVPR. 2009 (pp. 248-255). IEEE.

[22]Krizhevsky, A., Sutskever, I., \& Hinton, G. E. (2012). Imagenet classification

with deep convolutional neural networks. In Advances in neural information processing systems (pp. 1097-1105).

[23]Sermanet, P., Eigen, D., Zhang, X., Mathieu, M., Fergus, R., \& LeCun, Y. (2013). Overfeat: Integrated recognition, localization and detection using convolutional networks. (pp. 1-16). arXiv preprint arXiv:13126229.

[24] Szegedy, C., Liu, W., Jia, Y., Sermanet, P., Reed, S., Anguelov, D., et al. (2015). Going deeper with convolutions. In 2015 IEEE Conference on Computer Vision and Pattern Recognition (CVPR) (pp. 1-9).

[25] Chandrakumar, T., \& Kathirvel, R. (2016). Classifying diabetic retinopathy using deep learning architecture. International Journal of Engineering Research \& Technology (IJERT), 5(6), 19-24.

[26] Srivastava, N., Hinton, G., Krizhevsky, A., Sutskever, I., \& Salakhutdinov, R. (2014). Dropout: A simple way to prevent neural networks from overfitting. The Journal of Machine Learning Research, 15(1), 1929-1958.

[27] Wan, L., Zeiler, M., Zhang, S., Le Cun, Y., \& Fergus, R. (2013) Regularization of neural networks using dropconnect. In International Conference on Machine Learning. (pp. 1058-1066).

[28] Pedraza 1.,Vargas C., Narvaez F., Duran O., Munoz E., Romero E. (2015). An open access thyroid ultrasound-image Database. 10th International Symposium on Medical Information Processing and Analysis, doi: $10.1117 / 12.2073532$ 